\title{
Expanding Capacity in Nonprofit Organizations Using the Baldrige Excellence Framework (A Single Case Study)
}

\author{
Reginald A. Stanley \\ Walden University, Minneapolis, MN, USA \\ Email: reginaldstanley@me.com
}

How to cite this paper: Stanley, R. A. (2021). Expanding Capacity in Nonprofit Organizations Using the Baldrige Excellence Framework (A Single Case Study). Open Journal of Business and Management, 9, 701-730.

https://doi.org/10.4236/ojbm.2021.92037

Received: January 15, 2021

Accepted: March 19, 2021

Published: March 22, 2021

Copyright $\odot 2021$ by author(s) and Scientific Research Publishing Inc. This work is licensed under the Creative Commons Attribution International License (CC BY 4.0).

http://creativecommons.org/licenses/by/4.0/

\begin{abstract}
Grounded in general system theory, the purpose of this qualitative single case study was to explore strategies leaders of a small nonprofit organization in southern California used to grow their organization to serve a larger population. The participants comprised 3 nonprofit leaders with documented success at developing and growing their business. Data were collected from semistructured interviews and organizational documentation. Thematic analysis was used to analyze the data; 4 themes emerged: effective fundraising cycles, leader development, strategic planning, and long-term growth. The results of the study indicated nonprofit leaders create standard operating procedures and focus on short and long-term goals such as growth, hiring, and recruitment to support growth and development planning for future leaders. The implications for positive social change include the possibility of nonprofit organization leaders to offer expansion and growth strategies to increase their organizations' capacity, enabling them to positively transform their communities by improving and maintaining available services and adding additional services.
\end{abstract}

\section{Keywords}

Baldrige Excellence Framework, Expanding Capacity, Nonprofit Organization (NPO), Small Business

\section{Background and Introduction}

The nonprofit segment has shown stable and dependable growth over the past decade in size and monetary gain, exceeding the growth of for-profit and government counterparts (Kang, 2016). The nonprofit sector has enticed the attention of researchers at the international level over the past 2 decades (Mourão, 
Pereira, \& Moreira, 2017). This attention involves the nonprofit segment's responsibility in providing social services, a considerable economic strength for job establishment, and gross added value in national economies (Mourão et al., 2017).

Although there has been an overall increase in the nonprofit segment over the past decade (Kang, 2016), over the past 2 years, one in four top nonprofit leaders have resigned, and nearly that same number are planning to leave in the next 2 years (Landles-Cobb, Kramer, \& Milway, 2016). This break resulted from a ubiquitous leadership development shortage in the nonprofit sector (Landles-Cobb et al., 2016). Nonprofit organizations tend to function in a progressively competitive environment; scholars, policymakers, and experts agree in recognizing that balancing money and mission becomes a primary management issue (Sanzo-Perez, Rey-García, \& Álvarez-González, 2017). Understanding how to develop strategies to expand capacity will assist nonprofit organization leaders when engaging a larger population.

This qualitative single case study was to explore strategies leaders of a small nonprofit organization in southern California used to grow their organization to serve a larger population. The participants comprised 3 nonprofit leaders with documented success at developing and growing their business. This study is structured by Section one: the abstract, purpose statement, the research question, assumptions, limitations, and delimitations and the literature review. In addition Section two contains the research structure, data collection and analysis. Section three contains the findings, recommendations, and conclusion.

\section{Purpose Statement}

The purpose of this qualitative single-case study was to explore strategies nonprofit leaders use to expand their organizational capacity to serve a larger population. The target population included senior leaders of a single nonprofit organization who effectively executed strategies to expand a nonprofit organization's capacity in southern California.

\section{Research Question}

The Central Research guiding this study was what strategies do nonprofit leaders use to expand organizational capacity to serve a larger population? Data derived from flexible interview questions, records, notes from the interviews, organizational documents, and the organization's website.

\section{Assumptions, Limitations, and Delimitations}

Assumptions are precise opinions linked to the study that a scholar trusts to be factual or valid (Akaeze, 2016). In this study, there were three assumptions. This study's first assumption was that participants would be honest, transparent, and upfront with their responses to the interview questions. Second, I assumed a qualitative single-case study design was best for this study. Finally, I assumed using 
the 2017-2018 Baldrige Excellence Framework and criteria to assess my client organization offered the best system viewpoint for evaluating the research question. Limitations are those characteristics of a study that researchers do not control (Akaeze, 2016). Access to the participants was limited because of the geographic location. Interviews were primarily conducted over the phone. The participants' viewpoints may not be a true representation of other nonprofit organizations in the same region.

Delimitations denote the scope and restrictions, as set by a researcher (Akaeze, 2016). This study focuses on nonprofit organizations leaders' strategies to expand capacity in Southern California. One delimitation of the study was the client's location; all participants were from a single nonprofit organization located in Southern California. Other areas in California were outside the boundaries of the study. Other types of businesses were not in the boundaries of the study. Also other areas in the United States and abroad were not in the boundaries of the study.

\section{Significance of the Study}

\section{Contribution to Business Practice}

This study is of value to business practice because I provided the leadership perspective gained by senior leaders in expanding nonprofit organizations' capacity. Additionally, the research results potentially point out a foundation for nonprofit organizations to adjust their business practices in certain areas operationally. Leaders must remain up to date on competitive business practices to modify and revolutionize enduring relevance (Choi, 2016). Furthermore, leaders from nonprofit organizations might better understand this study's findings to increase support to communities, secure necessary funding, and improve effectiveness.

\section{Implementation for Social Change}

The implications for positive social change from this study include the potential to successfully contribute to nonprofit leaders' effective strategies to increase their organizational capacity. When nonprofit senior leaders effectively expand their capacity, it enables them to provide the support needed to serve additional community members.

\section{A Review of the Academic Literature}

\section{General System Theory}

A concentrated attempt to create a general theory of systems came into being in the 1950s with the formation of the Society for the Advancement of General Systems Theory, later incorporated as the Society for General Systems Research, and later renamed the International Society for the Systems Sciences (Rousseau, 2017). The society was created to pursue the implications of an influential idea suggested by Ludwig von Bertalanffy (Rousseau, 2017). Von Bertalanffy noted that in nature there are structural patterns and practical processes that persist 
with the same form despite variations in scale and composition (Rousseau, 2017).

Von Bertalanffy (1950) defined GST as a theory used to determine the association between two entities, or a system, in 1928 (Caws, 2015; von Bertalanffy, 1950, 1953). Von Bertalanffy introduced GST in 1928 and is considered the GST founder, which he identified as a tool used for many problems (Caws, 2015; von Bertalanffy, 1950, 1953). To advance the theory, the theorist presented GST in a German-language periodical in 1937, with the original document remaining unpublished until 1945 (von Bertalanffy, 1968). Von Bertalanffy originally based GST on the connection among biological systems and the symbiosis between plant and animal communities (von Bertalanffy, 1950, 1953). A system must continue to be open for vigor to move and to exchange facts among two or more parties (von Bertalanffy, 1968). I used GST as the conceptual framework to explore strategies nonprofit leaders use to expand their organizational capacity to support a larger population.

Von Bertalanffy $(1953,1968)$ extended systems theory by exploring connections among relationships, goals, problems, and perspectives with emphasis on understanding procedures both internal and external to discovered systems. With this growth, von Bertalanffy $(1953,1968)$ netted sets of objects as the system and diverted attention to expounding and understanding difficult relationships and phenomena among components. Additionally, while examining associations between organizational wholes, von Bertalanffy (1968) concentrated on individualities within systems as a contributor to the common elements of the group. Caws (2015) solidified these findings and advances in GST from the viewpoint of comprehensive systems in the science crusade of pulling together structures and affiliations. Added advances for GST encompassed improvement in both theory and science as identifying and reporting on collaborations between systems (Caws, 2015).

The framework of GST extended into the business management arena with the documenting of a business enterprise functioning as a social structure of cultural interrelationships. Human organizations and societies bear a resemblance to open systems inside a biological structure identified by von Bertalanffy (Rousseau, 2017). Human organizations and cultures contribute to nonstop development by working together within their environments and creating various procedures and properties (Valentinov \& Chatalova, 2014). As an alternative to considering organizations established exclusively on their separate components, scholars look through the lens of GST organizational structures (Caws, 2015). Through this lens, scholars explore the numerous elements within organizations and the collaboration of these components as an entire unit.

Hitt, $\mathrm{Xu}$, and Carnes (2016) pronounced that the use of theories, such as GST, aids scholars with understanding the phenomenon associated with operations management. The use of theories in operations management increases the researcher's capacity to offer profounder understanding about an organization's 
exploration questions (Hitt et al., 2016). Ceric (2015) explored how GST added value, by examining it from the aspect of information communication technology. The value generated for a business stemmed from the difficult exchanges among the organizational divisions and information communication technology (Ceric, 2015). Fantazy, Tipu, and Kumar (2016) used GST to hypothesize the characteristics and comparative directness of supply chains and concluded the effect on organizational performance. Fantazy et al. (2016) used GST lens because organizational supply chains reflect the open system viewpoint established within GST.

Objects, characteristics, inner associations, and system environments are all critical elements of GST (von Bertalanffy, 1968). According to Broks (2016), a system is a series of items that intertwine to achieve a specific goal and possibly alter information to attain a specified outcome. Proponents of GST continue to solidify both values and assumptions of the theory. Even though newer theories shorten the title to systems theory, pivotal points revolve around world phenomena as collected systems, interrelated parts, and continuous change between systems and the interconnected parts that encompass the entire structure (Broks, 2016).

Von Bertalanffy $(1950,1953)$ frequently encouraged his goal of assisting others to grow into experts of the technological forces of the world, rather than victims. Von Bertalanffy $(1968,1972)$ concentrated on the individual as a vital element of social organizations, while instituting efforts concerning entrenching a grassroots involvement in global, participative democracy with the objective of a progressively worldwide and comprehensive perspective in others. Von Bertalanffy $(1950,1953,1968)$ also highlighted enlarging the system through assessing the process of probing goals or problems from the worldwide viewpoint and a variety of lenses by concentrating on developing innovative ways to establish connections and attain sustainability. Von Bertalanffy's effort to move GST from the biological realm to the social realm was met with opposition for 16 years, but many scholars exhibited curiosity in the GST as a viable social theory (Caws, 2015).

Rousseau (2017) advanced the systems theory in the area of behavioral science and recognized that this theory could bring together conversations in many academic fields. Specifically, systems focused on both objective and subjective properties, along with relational approaches to an organization as a whole can benefit from a systems theory approach (Rousseau, 2017). Although advances have been made, the growth of a general theory of systems has been hampered by the absence of progress with classifying and refining scientific general systems principles that could support the methodical discovery of systems laws and development of prognostic systems theories (Rousseau, 2017).

The general systems theory has been projected as a basis for the amalgamation of science. The open systems model has enthused many new conceptualizations in organization theory and management practice (Kast \& Rosenzweit, 1972). 
However, experience in applying these concepts suggests numerous unresolved quandaries (Kast \& Rosenzweit, 1972). Contingency opinions characterize steps toward less thought, more obvious patterns of relationships, and more applicable theory (Kast \& Rosenzweit, 1972). Biological and social scientists commonly embrace systems concepts (Kast \& Rosenzweit, 1972). Several organization and management theorists seem anxious to identify with this crusade and to contribute to the development of a methodology which offer the ultimate-the merger of all science into one impressive conceptual model (Kast \& Rosenzweit, 1972). The general systems theory appears to deliver a relief from the limitations of more mechanical methods and a justification for declining ideologies based on moderately closed-system thinking (Kast \& Rosenzweit, 1972). This theory provides the model for organization and management theorists to crank into their systems model all of the varied knowledge from pertinent underlying disciplines (Kast \& Rosenzweit, 1972).

Undoubtedly, the complete range of thought about systems cannot be covered by one article (Drake \& Schwarz, 2010). According to Drake and Schwarz (2010) they concentrated on peer-reviewed articles that were associated with scientific world. To explore present philosophies of GST, its presence in those articles aids as an instrument and gauge for discerning how GST has been advanced (Drake \& Schwarz, 2010). Drake and Schwarz relate our more detailed investigation of articles to GST references relevant to science and philosophy out of 161 articles appearing from 1995 to 2006. Several articles deal with the applications of GST in areas such as engineering and management, which we do not discuss (Drake \& Schwarz, 2010). Instead, the particular article focuses on contributions in the areas of science and philosophy in terms of critiques, additional developments, possible limitations of GST and related world views (Drake \& Schwarz, 2010). From the beginning of GST, the purpose was to institute a formal methodology to be used in several scientific disciplines, just as probability theory is a mathematical method that can be used in numerous fields (Drake \& Schwarz, 2010).

Scholars have advanced the theory as a study of patterns of relationships amongst numerous systems, fields, areas of knowledge, or subsystems (Caws, 2015; von Bertalanffy, 1968). Progress in this area has been slow, despite significant progress in other areas of systems science. Developments in this area have been slow, in spite of noteworthy progress in other areas of systems science (Rousseau, 2017). Today we have several systems thinking methodologies in management science and systems engineering, and about a dozen specialized systems theories, but so far, no wide-ranging systems principles that are methodical in the sense of being accurate and measurable have been established (Rousseau, 2017). The general systems principles we do have are signified by a lesser variety of ideas and schemes, but the concepts are questionable, and the propositions are experiential and articulated in qualitative terms (Rousseau, 2017). These ideologies offer valuable guiding alignments for making decisions or acting in a systemic context, but being flexible and explanatory rather than 
precise and descriptive they do not allow the growth of predictive systems theories.

The footsteps are noticeable as phenomena and scientific disciplines (Malecic, 2017). Diverse scientific disciplines frequently use unlike methodologies and terminologies for the similar characteristics of reality (Malecic, 2017). Systemness in nature can for example be discovered in major mechanics, science of life and consciousness, and chaos. More specifically, a solid contender for GST should disclose whether the standards of systemness in reference to the prior sentence are pertinent and if they should be enhanced or substituted by some additional systems (Malecic, 2017). General systems theory has grown in its acceptance over the previous 25 years due to its capability to serve as a worldwide theoretical model of existing systems, including diverse biological, social, and behavioral phenomena (Perry Jr., 1972).

An analysis of some of the standards and expectations of general systems theory might help to disclose likely restrictions involved in its acceptance as the main paradigm for probing into the phenomena. Perry Jr. (1972) studied some of the principles and expectations of GST that: countless ideas confined in GST establishes a nonrefutable hypothesis which aids social philosophy to include those of science; the rudimentary dogma of GST are held in shared with mechanical functionalism making GST the topic of conversation to the comparable criticisms frequently connected with the functionalist method within sociology; and the premises of consensus, evolution, and hierarchy are rudimentary to GST designs created within the administrative theory (Perry Jr., 1972).

These principles and beliefs cause theories created within the model of GST to be ideologically prejudiced toward an order standpoint which highlights steadiness and system preservation rather than change (Perry Jr., 1972). General systems theory is not to be disparaged because it appears to have a specific value alignment; it has this in common with nearly every framework used for social inquiry (Perry Jr., 1972).

Researchers reduced the name of the GST to systems theory, as researchers advanced the system into a structure to assess and categorize the world (von Bertalanffy, 1968). I selected the GST because of the legitimacy the theory brings to this study. I believe, as a foundational theory, GST is a good fit not only to gain an understanding on sustainable strategies, but also how systems and subsystems inside an organization relationship or rely on each other. Future scholars might gain an understanding when using the GST as an influential theory for studies about capacity; however, a 21st-century theory may produce dissimilar results. Additionally, using a 21st-century theory could provide prospective scholars with a more recent and appropriate worldview to explore sustainability.

\section{Managers and Expansion Strategy}

When considering expansion; transferring organization vision to strategy actions is the leader's obligation, whereas business strategy employment is the duty 
of managers and leaders' subordinates (Saini \& Sengupta, 2016). Strategy implementation includes competent managers with effective performances that activate procedures and methods for leaders desired visionary achievement (Joyce \& Slocum, 2012). Therefore, effective strategy implementation is an element of the management capacities and leadership style effectiveness.

Capacity expansion commonly necessitates large capital expenditure on liquid assets (Momani, Al-Hawari, \& Mousa, 2016). Consequently, decisions to increase capacity must support the organization's strategic objectives and offer valued input for the planning process (Momani et al., 2016). Enduring functioning capacity growth requires irrevocable, uneven, and prolonged investments (Momani et al., 2016). Expansion is frequently the authority of managers of multinational companies (Ghorbal-Blal, 2011). Through the surge of the number of business elements, growth strategies are some of the most shadowed strategies of multinational corporations as they are often presumed to be equal to performance (Ghorbal-Blal, 2011). Evaluating a broader variety of strategies can decrease risk and sponsor choices that make the most of the company's worth (Ghorbal-Blal, 2011).

\section{Small Business}

A small business is one that typically has less than 500 employees. In 2016 small businesses accounted for 56.8 million workers, $99.7 \%$ of all businesses, and $50 \%$ of those employed in the United States (U.S. Small Business Administration, Office of Advocacy, 2016). The U.S. Small Business Administration, Office of Advocacy (2016) further defines small businesses as those organizations organized for-profit or not-for-profit; are functioned and owned independently and are known and can vary by industry. Normally, owners run small businesses as partnerships, s-corporations, or sole proprietorships. Their management follows precise tax guidelines (Pugna, Miclea, Negrea, \& Potra, 2016; U.S. Small Business Administration, Office of Advocacy, 2016).

Small business owners have an important part in the United States economy by producing jobs and driving modernization. The principal motive behind starting a new business is for the income the small business owner imagines he will earn from the operation of the business (Yusuf \& Schindehutte, 2000). Income is likely if the business can make a profit by earning more resources than it takes to operate the business. The business owner must center more on the business's strong points and put less emphasis on the rest (Lan, Bo, \& Baozhen, 2014). Factors that are a part of small business performance include, but are not limited to owner and manager characteristics, business strategy, and business characteristics (Blackburn, Hart, \& Wainwright, 2013).

The business owner's choices about where and what to concentrate on produce the organization's business strategy. The business strategy is how the organizations' leaders align the business with its surroundings to establish and sustain a competitive advantage by making the most of its assets, resources, and competencies in a complete manner (Gumusluoglu \& Acur, 2016; Palmer, 
Wright, \& Powers, 2001). Small business owners should align their limited capital to those activities that improve their business strategies (Blackburn et al., 2013; Lan et al., 2014). Some small business activities that improve small business strategies may be financial, commercial, and in some cases may be ethical (Garza, 2013). Small businesses leaders within an organization take control of the resources for human and physical capital (Campbell \& Park, 2017). No matter how you define a business and the difference between employee level and total assets, these companies increase and stabilize the national economies (Leonidou, Christodoulides, Kyrgidou, \& Palihawadana, 2017). Celec and Globocnik (2017) postulated that smaller organizations contribute to nationwide economies and are causes of economic growth. The income generation is a significant reason to get involved with small business operations and as business revenue surpasses operating expenditures, revenues surge, which ultimately drives accomplishment (Baumol, 2015).

\section{Nonprofit Organizations}

Nonprofit organizations support the community in noteworthy ways for example they depend heavily on philanthropic and government resourcing it is becoming more difficult to sustain, specifically in the wake of economic declines (Stecker, 2014). The presentation of social entrepreneurial ideologies, including social enterprise activities, can increase the sustainability of nonprofits' business model while strengthening management capacity and enhancing mission (Stecker, 2014). There are more than 1.4 million active nonprofits organizations in the United States, vying for scarcer and scarcer dollars, nonprofits must pursue new funding sources (Stecker, 2014).

\section{Failure of Nonprofit Organizations}

There are numerous theories or arguments why nonprofit organizations, known as the third sector, were created (Siddiqui, 2018). We call this sector (voluntary, philanthropic, non-governmental, and nonprofit) fluctuations depending upon the viewpoint. Unfortunately, this segment's vital component has been lost in our journey for superior legitimacy through lawful and managerial classification (Siddiqui, 2018). Several nonprofit organizations obtain grants, gifts, or donations with a restriction (Gilbert, 2017). Nonprofit organizational leaders receive donations but should prove these grants or donations followed legal and ethical guidelines (Gilbert, 2017). When funding or gifts are received, this is the best time to create a process that tracks these restricted gifts or grants that demonstrate how the money was applied to the intended item (Gilbert, 2017). No nonprofit leader wants to deal with an audit and not have documents to support their donations and how they were used (Gilbert, 2017). Unfortunately, nonprofit organizations' leadership does not discuss these issues until it is too late (Gilbert, 2017). This often leads to the failure of nonprofit organizations. Just like nonprofit organizations not all small businesses succeed after 5 years as approximately $50 \%$ fail, and $30 \%$ remain in business at the 10 -year mark (Hibb- 
ler-Britt \& Sussan, 2015). The ability to remain in business may increase over time if businesses can continue beyond the 5 years and, and if the national economy impact organizational efforts (U.S. Small Business Administration, Office of Advocacy, 2016). Possible failure issues during the beginning phase of small business start-ups comprise limited funding, minimal management skills, failure to have a proper strategic plan in place, and the failure of management to retain the right mix of employees (Bennett, 2016). According to Bennett (2016) there are certain requirements and competencies that are vital for long-term business success, and its essential that they are in place from the inception of operations. According to Manso (2017), concentrating on innovation points out risk-taking as a share of small business processes. With the way technology is expanding, comprehending technological innovation risk tolerance will assist with long-term success and performance. Maintaining the proper human capital, longer contracts, also aids long-term success instead of business failure (Manso, 2017).

If strategic planning is not accomplished, to include thoroughly focusing on detailed business strategies, diminished company fiscal performance follows (Bennett, 2016; Mellat-Parast, Golmohammadi, McFadden, \& Miller, 2015). Reduced financial performance, connected to unstable economies coupled with augmented unemployment, is an additional business failure sign (Sassen, 2016). Monelos, Sanchez, and Lopez (2014) gathered the information for small to medium business failure prediction models and attested fiscal performance as a prime business failure indicator. Additional failure measures include overdue financial payments, approval of diminished employee qualifications, and an absence of quality values (Monelos et al., 2014). In addition to the monetary side of small business failure, lapses in understanding growth; functioning processes; management processes; accepting market space and market share; and customer buying behaviors also contribute to small business failures (Cavan, 2016; Choi, Rupasingha, Robertson, \& Green Leigh, 2017; Luo \& Stark, 2015).

Business success is not a guarantee or programmed; probable causes for failure could offer an opportunity for success. The more the competition, the more sales are decreased, and location and inadequate technology all contribute to business failures (Choi et al., 2017; Franca, de Aragao Gomes, Machado, \& Russo, 2014). Integrating transformational business processes, employing ground-breaking technology, and reducing tangible asset acquisitions, smaller organization leaders may thrust small business existence beyond 5 years (Franca et al., 2014). Additionally, understanding business failure drawbacks before beginning the process of closing the business is also vital (Coad, 2014). Precise variables describe failure in the business segment; these variables can be restrained, and provide fundamentals for accomplishment versus failure (Scherger, Vigier, \& Barbera-Marine, 2014; Wang, Gopal, Shankar, \& Pancras, 2015). By understanding the details for failure, organization leaders may fend off business closure and thrust the company into long-term success. 


\section{Research Method and Design}

\section{Research Method}

I used the qualitative research method to explore organizational expansion strategies for a developed, small nonprofit organization conducting business in southern California. Scholars use qualitative research methods to collect information and explore the phenomenon of individuals and groups (Park \& Park, 2016). The qualitative study method is unlike the quantitative research method because of science, answering what, and testing hypotheses for arithmetic measurements (Lincoln \& Guba, 1985; Park \& Park, 2016). Qualitative research entails an in-depth analysis of the structural processes and people without a predetermined bias. Scholars using the qualitative research method can attain information from contributors when using numerous data-gathering instruments. Qualitative data are narrative in nature and help discover individuals' lived experiences (Ross, Iguchi, \& Panicker, 2018).

Understanding the difference between qualitative and quantitative research is vital when selecting the proper research method to address a research question. Qualitative studies can include discovering delicate issues using semistructured interviews to garner vital information from contributors (Yazan, 2015).

\section{Research Design}

I selected a single case study design for this study. Researchers choosing the case study method seek to examine and address the how, what, and why of contributors' understandings and insights within their usual context (Ridder, 2017). According to Yin (2018), there are four types of case study design: 1) embedded multiple units of analysis design, 2) holistic single unit, 3) multiple case design, and 4) single-case design. Saunders, Lewis, and Thornhill (2015) stated that a single case study enables a scholar to gain a detailed understanding of the contributors. The single case study is a set of procedures and processes used to gather, examine, and measure variables being discovered or observed in the research problem (Alavi, Archibald, McMaster, Lopez, \& Cleary, 2018). According to Guetterman and Fetters (2018), the research design's objective is to address the research question and advance a particular idea.

Single case studies involve researchers using questions without restraints to help motivate contributors to provide widespread answers to well-established questions (Windsong, 2018), which aids in reaching data saturation. Data saturation is when the same scholar or other scholars can reproduce the outcomes when they duplicate a study with different contributors (Marshall \& Rossman, 2016). Data saturation aids in ensuring the validity of a study. Failure to reach data saturation has an undesirable effect on the validity and quality (Fusch \& Ness, 2015). In this study, I interviewed until I confirmed data saturation when no additional information or topics arose.

\section{Population and Sampling}

The populace I selected for my first sample of contributors was from a small 
nonprofit organization operating in southern California. I used a purposeful sampling method consisting of three to five participants for this study. The sample size depends on the purpose of a study and the number of contributors required to answer the research question (Saunders et al., 2015). Duan, Bhaumik, Palinkas, and Hoagwood (2014) stated that purposeful sampling finds mutual patterns to articulate and assess assumptions. Researchers should choose the sample size with the highest chance of reaching data saturation (Marshall \& Rossman, 2016). I confirmed that I reached data saturation by interviewing several contributors until no new information emerged.

I used purposeful sampling for this study as it aligned with the direction and intent of the study. Purposeful sampling frequently befalls before gathering data, while theoretical sampling happens in combination with data collection (Yazan, 2015). Using purposeful sampling is a justified method when the sample populace was visible and well-defined (Fusch \& Ness, 2015). I established a weekly communication with the senior leader via phone conference throughout the service agreement. Telephone interviews and document reviews were the principal methods for gathering data for qualitative case studies (Ridder, 2017). In qualitative studies, numerous contacts with contributors are essential to guarantee data saturation, as scholars regulate recommendations and new themes (Saunders et al., 2015). I associated the interview questions with the 2018 Baldrige Excellence Performance Framework. I studied the data to ensure that saturation had indeed occurred with the contributors. Once data and information were collected from semistructured conferences, and evaluation of company material revealed no new information, data saturation occurred.

\section{Data Collection Instruments}

In qualitative research, the scholar, in many cases, is the principal instrument for collecting data (Ridder, 2017; Van den Berg \& Struwig, 2017). I served as the primary data collection, data storage, and data analysis instrument for this qualitative single case study. Researchers gather data utilizing different qualitative research methods, including but not limited to interviews, transcripts, or focus group discussions (Ridder, 2017). I collected data from flexible interview questions, records, and notes from the interviews, organizational documents, and the organization's website. The research questions and objectives decided methods to collect data and how to creatively use the data (Gummer \& Mandinach, 2015).

I used the 2017-2018 Baldrige Performance Excellence Framework to attain a well-rounded understanding of its processes and their performance that impacted its growth strategy. Scholars use the Baldrige Performance Excellence Framework to collect data in the following areas: 1) customers; 2) workforce; 3) operations; 4) knowledge management, analysis and 5) leadership; 6) customer; and 7) results (Walden University, 2017). I conducted open-ended interviews with all contributors. Each interview's average time was 30 minutes in length, and I added additional time if needed. Researchers were leading interviews to 
place an interviewing protocol before the interviews to guarantee consistency with the interviewing process (Windsong, 2018). The interview protocol outline comprised of multiple stages, which included 1) utilizing an associate tracking system for accuracy, 2) obtain and examine discussions amongst researcher and contributor, 3) thorough outline of the interview protocol with all contributors, and 4) ensure the interview questions aligned with the research question. I maintained this qualitative single case study's integrity by following the member checking and the interview protocol.

\section{Data Collection Techniques}

The process of collecting data included searching for strategies that nonprofit leaders use to increase capacity. The data collection method chosen for this qualitative single case study was semistructured telephonic interviews, transcript reviews, notes, e-mails, the organization's website, and additional supporting documentation. Researchers use interviews to discover workplace complexities in more considerable depth than reviewing documents that have been archived (Boddy, 2016). Researchers' record in-person and telephone interviews to get a greater understanding of the contributor views and ensure accuracy when organizing records for analysis (Phillips, Borry, \& Shabani, 2017). Before the interview sessions, I sent e-mails to ensure the date and time were correct. Interviews were conducted by telephone as the principal method of gathering information from each contributor. I ensured the semistructured interview questions' alignment with the topic and the 2017-2018 Baldrige Excellence Framework.

Researchers must recognize that utilizing interviews as the primary data collection technique has both advantages and disadvantages. For example, conducting contributor interviews is a critical task, and researchers must allot sufficient time and training to gain proficiency. Some of the best researchers have an issue with being personally bias and preserving the interview protocol (Windsong, 2018). Robinson (2014) posited semistructured interview is an asset in conducting qualitative case study research. Researchers and contributors might participate in noteworthy pontification throughout semistructured interviews (Miracle, 2016). A review of company documents offers added information through the methodological triangulation process (Yin, 2018). Additionally, I reviewed internal and external documents to include the company's financial report, website, and notes from interviews to better understand the organization and its potential for increasing capacity.

Yin (2018) conveyed that document reviews can offer added support to improve interview accurateness. Conversely, Windsong (2018) contended that countless researchers lack the experience of reviewing many documents because of the time it takes and the cost. Varpio and Meyer (2017) conducted research and suggested members check to ensure the research results' validity to the contributor's experience. The member checking process I used allowed contributors to authenticate my interpretation of their answers from the semistructured in- 
terviews.

\section{Data Analysis}

Ganapathy (2016) posited researchers use a qualitative data analysis process to gain knowledge of new ideas and improve their understanding of the phenomenon. Fusch and Ness (2015) stated that to gain data saturation, researchers use methodological triangulation. Methodological triangulation boosts reliability using numerous data sources to pinpoint new themes (Ganapathy, 2016). Researchers can use several data sources to reference data and guarantee correctness from semistructured interviews and historical documents (Windsong, 2018). Researchers frequently triangulate data as part of their data collection strategy, where the details of the outcomes are in the case description (Ridder, 2017).

For this study, I used methodological triangulation to explore the data from semistructured interviews, historical data, financial reports, social media, and company websites. I translated the interview recordings at the end of each session and did associate checking to ensure I received each participant's proper message. After studying the internal and external data and translating the interview questions, I recorded the raw data utilizing excel and a color-coding process. Researchers choose a coding process to categorize and develop themes from transcripts and shape and highlight qualitative data (Kroll, 2017; Vaughn \& Turner, 2016). Using color-coding helped to create a narrative and the most important themes of the study. Coding is a simple but adaptable and respectable instrument that enables researchers to reorganize the raw data into groups for the phase of the analysis (Saunders et al., 2015). I studied the data sources, and methodological triangulation enabled me to explore leaders' ability to increase their capacity in a small nonprofit organization.

I maintained awareness of personal biases, kept an open mind, and was receptive to new information because of my knowledge of and working with other nonprofit organizations. Member checking was used during the data analysis phase to ensure the correctness of the information. Irvine and Irvine (2016) posited that researchers conduct data analysis to contribute to the field of study by incorporating scholarly literature and new themes from case studies. Researchers show a relationship between the findings with the literature and conceptual framework to validate, invalidate, and extend the existing literature (Marshall \& Rossman, 2016). I used the 2017-2018 Baldrige Excellence Framework to gather and recognize new themes and arrange the results with the conceptual framework and literature that contribute to increasing a small nonprofit organization's capacity.

\section{Reliability and Validity}

Abdalla, Oliveira, Azevedo, and Gonzalez (2018) suggested to have value in qualitative research; researchers implement procedures to guarantee credibility, 
transferability, confirmability, and reliability in the research study. Biases surge when a scholar discovers how challenging it is to measure the quality of the study (East, 2016). Establishing trustworthiness in qualitative research helps researchers to improve reliability in the research methods and results as well as lessens bias and errors (Yin, 2018). Integrating procedural strategies in qualitative research enhances the study's reliability (Noble \& Smith, 2015). Reliability dictates precisely how to address dependability (Windsong, 2018). Reliability is a vital characteristic of research superiority, and it is not adequate alone to ensure good quality research (Saunders et al., 2015). Case study researchers must confirm reliability by observing the case study databases and protocols (Yazan, 2015). Following an interview protocol aids in improving the reliability of the case study research by managing the data collection process (Yin, 2018). This study's reliability started with a determined sampling method to acquire useful data related to the phenomenon.

I enhanced the dependability of this study by utilizing methodological triangulation and member checking. Member checking verifies the correctness of data gathered, improves validity, and establishes trust in the research process (Chen, 2016; Debono, Greenfield, Testa, Mumford, Hogden, Pawsey, \& Braithwaite, 2017; Thomas, 2017; Varpio \& Meyer, 2017). Member checking in this study enabled contributors to guarantee explanations made sense in the way they aligned with their lived experience. Dependability is an equivalent condition to the reliability to track developing changes to a phenomenon and account for how others can comprehend and assess the data (Lewis, 2015). Researchers can triangulate semistructured coded data, notes, documents, and interviews to improve qualitative research consistency (Saldana, 2015). Additionally, member authentication and collaboration are vital in qualitative research (Levy, 2015). Data saturation includes interviewing sufficient contributors to a point in which no new information or themes appear (Fusch \& Ness, 2015). I reached data saturation upon completing the interviews of three contributors. I gathered data from the interview questions and reviewed transcripts to effect reliability through the interview protocol process, ensuring reliability and questions that were asked were unrestricted for all participants. Member checking enabled the participants to guarantee their responses made sense. If researchers are encouraging participants to take part in member checking, the researcher must present the analyzed data in a rewarding way (Birt, Scott, Cavers, Campbell, \& Walter, 2016). Reaching data saturation will help assure the dependability of the findings.

This study aimed to explore dependable and valid processes and data that reduce the chance of bias and misinterpretation. Noble and Smith (2015) posited bias in research diminutions the validity and reliability of the study. Researchers that gather data from several sources increase the validity and reduce bias (Chiniara \& Bentein, 2016; Starr, 2014). Likewise, researchers utilize internal and external validity methods to establish data accuracy (Ridder, 2017). Researchers 
can improve credibility by member reviewing contributors' transcripts, through triangulation, interview protocol, and data interpretation (Marshall \& Rossman, 2016). I established qualitative credibility by way of member checking of data interpretation, triangulation. I tracked the interview protocol to ensure my summary represented the phenomenon from the participants' standpoint and document analysis.

Prolonged research includes building relationships, trustworthiness, and gathering adequate data (Park \& Park, 2016). Researchers can improve confirmability by adequately verifying outcomes (Mihaela, 2017). I ensured confirmability by asking meaningful questions throughout the interview process and succeeding with member checking of the questioning, data interpretation, and triangulation. Adjusting external validity to qualitative research is challenging because the small sample size reduces the transferring of studies (Saunders et al., 2015). Collecting information from several sources, transcribing notes from the interview, using an interview protocol, and having $\mathrm{ABC}$ evaluate my findings enabled me to reduce bias.

Kroll (2017) suggested that researchers attain the dependability of a qualitative study once other readers have the chance to determine the transferability of the study. Yin (2018) concluded that thoroughness is a vital element of qualitative research because it necessitates researchers to apply current philosophies, use existing literature, and add data that reinforces the qualitative research and propose better awareness for future researchers. The GST includes a feasible way to quantify a company's accomplishments. General System Theory maintained the value that nonprofit organization leaders placed on increasing their nonprofit organization's capacity more significant than the present capacity and understanding the problematic structures essential to withstand long-term development and profitability.

\section{Findings}

\section{Product and Process Results}

$A B C$ is a nonprofit organization that operates in southern California for over 20 years. This business location was established to support the immediate needs of the community and assist families in need. This business location is looking to expand its capacity to serve more families and provide more services to the community.

$\mathrm{ABC}$ strives to create change in the community through persistent advocacy and outstanding customer service. The leaders of $A B C$ always remain active in the community by ensuring those in need are well informed. ABC leaders remain relevant in the community by providing single mothers and fathers who have the appropriate skills they require to become self-sufficient and their children exposed to proper nutrition and healthy living. At this business location, $A B C$ established work processes are operating efficiently and effectively because the disciplined staff are ensuring they are utilizing best practices, understanding 
their clients' needs, and ensuring they are following the applicable safety measures when dealing with clients.

\section{Customer Results}

$\mathrm{ABC}$ leadership has established an effective and efficient system for excellent customer services and listening to customer's needs. These systems were established with $\mathrm{ABC}$ mission and vision in mind. The leaders of $\mathrm{ABC}$ screen feedback from customers and follow industry trends to improve their future growth strategies. The most important growth step at this business location is opening a store where clients can purchase clothes and other items at a reduced cost. This has helped $\mathrm{ABC}$ to expand their brand and increase its customer base. $\mathrm{ABC}$ continues to impact the local community by reducing unemployment and improving family's quality of life with the service they provide. To ensure this business location, to ensure they hear their clients' voice, they use various platforms such as Facebook, Instagram, and the organization website.

\section{Workforce Results}

Leadership at this business location reviewed results related to workforce safety, hiring, and recruiting efforts. Workforce result indicators for capacity and capability might include staffing across the organization and employee qualifications to meet professional development requirements (Baldrige Performance Excellence Framework, 2018). At this business location, the leadership built a culture of trust by openly sharing workforce performance data and a vision for their employees' future growth strategies. The leaders of $A B C$ at the location are heavily involved in developing and engaging with their workforce. The leadership is genuine about their organizational culture and well-being. The administration at this business location continuously considered the capacity and capabilities of their workforce.

\section{Leadership and Governance Results}

This business location does not have a governing board of directors. The executive director is responsible for $\mathrm{ABC}$ 's oversight and functions, and he develops policies for running the organization. The leadership is thoroughly involved with the day-to-day operations of the organization. The Executive Director involves the other leaders in the organization with strategic planning and communicating the workforce's outcomes and other stakeholders. Amenability with rules and regulations, tax laws, child development, social workers, employees, and their working conditions, and the terms and conditions of the SLAs are adhered to within the organization.

Ethically, ABC's leaders have established processes and procedures in place for business operations and interacting with the stakeholders. There are gauges in place for assessing leadership communication, ethically engaging with clients, interactions with the staff, compliance with laws, rules, and regulations are clearly defined. Best practices are put in place, along with business processes within the organization. This business location has a semi operational Facebook sight; they perform collaborative community services for families and conduct 
resident meetings within the high desert communities in Southern California.

\section{Financial and Market Results}

Business leaders at this location are attentive to the financial and market results of their organization. $\mathrm{ABC}$ leadership has put in place measures to track marketplace financial performance and their performance in the market. These indicators or measures are evident in $\mathrm{ABC}$ for measuring economic performance, market performance, and strategic execution. Just like with any organization, the financial goals of $\mathrm{ABC}$ have met some challenges. These goals include the purposes of the company and its programs. Every year, the goals for cost efficiency, grants, partnerships, and increasing donors' number are met.

Leadership endlessly monitors the execution of the strategic initiatives scheduled every financial year and has always accomplished its implementation goals. ABC had a revenue budget of USD 595 thousand in 2018, which they achieved except for the 2017 financial year. In ABC, every USD invested in a family produces a return of three USD to the society reducing the requirement for public assistance, increases taxable earning, and cost savings from crime reduction. Every USD invested in early childhood nurturing and education saves 10 USD in social costs.

\section{Key Themes}

A vital component of this study is understanding what essential processes the leaders of $A B C$ are using and how efficient these processes are. The key themes include the process strengths and process opportunities for process improvement utilizing the four factors for assessing processes: integration, learning, approach, and deployment. These themes for process improvement were attained after using categories one through six of the 2017-2018 Baldrige Excellence Framework and Criteria. The key themes from the results' opportunities and strengths for results improvement result from using four evaluation elements: integration, comparisons, trends, and levels.

Deployment is the approach that can be used across processes, and learning includes using intuition for impacting endless changes while being united among various components within an organization (Baldrige Performance Excellence Framework, 2018). An approach is made up of methods used to satisfy a process and must be repeatable, appropriate, and effective with the proper information (Baldrige Performance Excellence Framework, 2018). Comparison across organizations and the degree to which the result measures and spread over various actions, customers, processes, and products are comparison and integration, respectively (Baldrige Performance Excellence Framework, 2018). Levels and trends are the measurable performance and rate of performance enhancement, respectively (Baldrige Performance Excellence Framework, 2018). The alignment of a method with company needs and the degree to which processes, plans, measures, and other elements are synchronized within the organizations is assimilation (Baldrige Performance Excellence Framework, 2018).

Process Strengths. Process strengths are a vital aspect for ABC to expand 
beyond its current capacity. Their mission, vision support their processes and values, supporting their workforce, customers, collaborators, and stakeholders. Leadership supports the workforce, partners, suppliers, and stakeholders. $\mathrm{ABC}$ Leadership promotes widespread legal and ethical, responsibility amongst all members within the organization. Leaders within $\mathrm{ABC}$ provide a full spectrum of support to strengthen their communities.

$\mathrm{ABC}$ processes intend to support the achievement of the strategic objectives, pinpoint, and exploit strategic opportunities. $\mathrm{ABC}$ processes support and assist the workforce in capitalizing on its strategic advantages against a set of goals. The procedures are appropriately developed to help the leaders in the practical usage and distribution of the organization's resources. The performance metrics or measures are well-defined for the workforce, communities, customers, leadership, strategic partners, service and support programs, operations, knowledge management, and results; and these measures and metrics are effective.

At this business location, the leaders understand that the voice of the customer's needs an identity and assessment. At this business location, meeting the needs of the customers is to be expected because the processes are developed to run effectively and efficiently. The methods around identifying, designing, evaluating, and providing quality programs to customers are accurately defined in $\mathrm{ABC}$. They are determined to be useful as well as aligning with the organization's objectives. Also, there are thorough processes for constant learning and performance enhancement throughout the organization at this business location. The employees at this business location are engaged, satisfied, and motivated because of the process efficiency and effectiveness that have been put in place. The procedures are identified for workforce accomplishment, accessing benefits, and safety working efficiently and effectively.

Process Opportunities. Process strengths are a vital aspect for $A B C$ to expand beyond its current capacity. Their processes are supported by their mission, vision, and values, supporting their workforce, customers, collaborators, and stakeholders. Leadership supports the workforce, partners, suppliers, and stakeholders. ABC Leadership promotes widespread legal and ethical, responsibility amongst all members within the organization. Leaders within $A B C$ provide a full spectrum of support to strengthen their communities.

$A B C$ processes are intended to support the achievement of the strategic objectives, pinpoint, and exploit strategic opportunities. $A B C$ processes support and assist the workforce in capitalizing on its strategic advantages against a set of goals. The procedures are appropriately developed to help the leaders in the practical usage and distribution of the organization's resources. The performance metrics or measures are well-defined for the workforce, communities, customers, leadership, strategic partners, service and support programs, operations, knowledge management, and results; and these measures and metrics are effective.

At this business location, the leaders understand that the voice of the custom- 
er's needs an identity and assessment. At this business location, meeting the needs of the customers is to be expected because the processes are developed to run effectively and efficiently. The methods around identifying, designing, evaluating, and providing quality programs to customers are accurately defined in ABC. They are determined to be useful as well as aligning with the organization's objectives. Also, there are thorough processes for constant learning and performance enhancement throughout the organization at this business location. The employees at this business location are engaged, satisfied, and motivated because of the process efficiency and effectiveness that have been put in place. The procedures are identified for workforce accomplishment, accessing benefits, and safety working efficiently and effectively.

Results Strength. At this business location, the leadership's business strengths included 1) strong leadership, 2) mentorship, and 3) over 20 years of program performance. ABCs flexibility enables them to change courses when needed, adjust as the industry changes, and make sound decisions without a governing body's approval. At this business location, ABC leadership's energetic involvement within the community contributes to business familiarity, visibility across the community, and product advertising. This business location has a thrift store where donations from the store helped offset costs to families through store credit.

Results accomplishment is emerged in and across $A B C$ and connected from customers and products to organizational processes, strategic plans, and goals. Based on the results from semistructured interviews, business plan, and the Baldrige Performance Excellence Framework (2018), I determined that ABC leadership provided sound leadership in the areas of professional conduct and personal readiness. Building on the GST as the conceptual framework of this study, I learned that there is significant and robust communication amongst staff and leaders, which has contributed to the organization's resounding success. Another critical finding identified at the business location should include training for the next generation to take over and sustain the business. I also concluded that one person is making all the decisions on long-term growth strategy execution, which is hugely limiting.

Results Opportunities. ABC leaders at this business location have effective and efficient systems in place within the organization. The leadership must improve the measurement and execution of employees' chances for engagement and leadership development and eliminating one person from making all the decisions. The leaders at this business location have measures for measuring customer satisfaction internally, but it is essential to define external customer satisfaction. Additionally, leadership must outline future capacity and capability needs for the workforce. Learning and growth system, an outline for identifying changes in the workforce's knowledge, skills, and abilities, needs to be developed by the leadership. These objectives will energize leaders in the right direction in achieving these elements of survival and growth. 


\section{Applications to Professional Practice}

Nonprofit organizations contribute considerably to the growth of communities and the welfare of the community. These contributions to society are through their favorable social change policies and programs they operate (Stephan, Patterson, Kelly, \& Mair, 2016). The majority of small- and medium-sized enterprises tend to go out of business within 5 years after being established (Ifekwem \& Adedamola, 2016). At this business location, the leadership wants to grow and expand the capacity of the organization. In this study, I explored strategies that nonprofit business leaders use to grow and develop their organizational capacity. Four themes emerged: effective fundraising cycles, leader development, strategic planning, and long-term growth. Nonprofit business leaders can use the information from this single-case study to explore effective strategies leaders of a nonprofit organization use to expand their capacity. The growth of small mature nonprofit organizations is vital to the local community's development and growth (Greenspan \& Wooldridge, 2018). To increase capacity, nonprofit leaders need to build and implement strategies for sustainability and long-term growth.

Growth is the most vital characteristic of small business sustainability, productivity, and profitability (Bello \& Ivanov, 2014). Each contributor in this study provided valued vision into short- and long-term growth strategies. The results of the data collected from three contributors supported characteristics of the 2018 Baldrige Excellence Framework that are vital to organizational performance enhancement, which is: 1) leadership; 2) strategy; 3) customer; 4) measurement, analysis, and knowledge management; 5) operations; and 6) results. Business leaders reviewing the data in this case study may increase their knowledge on the strategies they can use to develop and expand a nonprofit business. Small business leaders may also garner an understanding of staff engagement methods and succession planning. Business leaders using the outcomes of this study to implement growth strategies might improve their organization's performance, capacity, sustainability, profitability, increase local tax revenue, and reduce unemployment. Using survival strategies recommended in this study, leaders can continue to impact social change strategies that benefit communities, the environment, families, and society.

\section{Implication for Social Change}

An implication for social change consists of offering small nonprofit businesses leaders with growth strategies to increase capacity above their current size. ABC contributes to improved families' ability to care for their families and reduce unemployment in the community. The growth of small businesses beyond year one is vital for the sustainment of an organization (Morgan \& Sisak, 2016). In 2015, small businesses accounted for $97.6 \%$ of organizations that exported goods, and $32.9 \%$ of the identified export value (U.S. Small Business Administration, Office of Advocacy, 2017). Most new businesses do not survive past the 
first 5 years; thus, reducing the tax revenue (Decker, Haltiwanger, Jarmin, \& Miranda, 2014).

The growth strategies outlined in this study could assist leaders of small nonprofit organizations in the development and implementation of short- and long-term goals to grow their organization beyond its capacity. The results of this qualitative single case study might also inspire leaders of small businesses to look for growth opportunities outside their comfort level, thus providing job growth, stability, and more contributions to local tax revenue.

\section{Recommendations for Further Action}

I recommend that $\mathrm{ABC}$ leaders use the data gathered from the Baldrige Performance Excellence Framework (2018) to develop their strengths, strengthen their weaknesses, benefit from opportunities presented to them, and limit external and internal threats. Qualitative researchers conducting parallel consulting case studies may benefit from completing a multiple case study of mature nonprofit organizations. I recommend that researchers understand the lack of growth strategies among nonprofit business leaders using various conceptual frameworks. I also recommend researchers contemplate using a multiple case study design to affirm the strategies that nonprofit leaders use to expand and grow their organization. The use of a multiple case study design will help researchers gain a broader knowledge of the strategies to expand and develop a nonprofit business in the western region of the United States, which will help in positively converting individuals, organizations, communities, the environment, and societies.

The recommendation given to $\mathrm{ABC}$ may help create a succession and growth strategic plan. At this business location, the executive director might seek to engage younger employees to determine their aspirations to learn management and leadership skills to sustain the business. The executive director at this business location might also consider training one of the current managers or hiring an additional manager to assist with running the day-to-day operations, freeing time for him to focus on succession and growth planning.

The results from this qualitative, single case study might contribute to the betterment of the organization and community practices of a small nonprofit organization. The influence on business practice contains the data and information garnered from using the Malcolm Baldrige Performance Excellence Framework on a small nonprofit business operating in the southern California. Social change contributions include increased tax revenue, lower unemployment, personal development, the betterment of families, and promoting business growth in the community.

This study's outcomes might contribute to positive social change by informing leaders of nonprofit organizations of the strategies for growth and expansion of their organization, which are necessary for long-term sustainability. Nonprofit organizations are a civil society with considerable influences on communities by 
making policies, innovation, cost-effectiveness, and participating in local communities' and public events (Appe, 2019).

\section{Conclusion}

Expansion and growth strategies secure long-term sustainability for nonprofit organizations. In this study, the leaders of nonprofit organizations posited that nonprofit leaders are looking for growth and expansion needed to employ effective strategic succession planning. Effective strategic succession planning is made up of defining long-term objectives, the definition of an implementation strategy, focused determination, environmental scanning, short-term goals, and evaluation and control of subsequent changes (Roth, 2015). Fundraising and strategic planning are parts of the strategies noted for the growth and expansion of a nonprofit business. A fundraising plan helps nonprofit organizations to accomplish their mission and is made up of three elements, which are 1) where we are? 2) Where do we want to be? and 3) How are we going to get there? (Sargeant \& Shang, 2017). Additionally, Sargeant and Shang (2017) pointed out that the components of a fundraising strategy are the overall direction, segmentation, and positioning.

Also, fundraising strategies chart a path of how a fundraising plan can be accomplished. Any nonprofit organization looking to achieve its goal of making a beneficial impact on society must have an effective fundraising strategy and plan. Tangible resources and financial valuation are additional strategies leaders use to expand the capacity of a nonprofit business. Human capital is one of the corporeal resources that systematizes other classes of resources to provide products. Assessments are desirable aspects of quality enhancement in any company (Gökalp \& Demirörs, 2017). Nonprofit organizations' leadership must repeatedly assess their tangible and monetary resources to continue to impact quality improvements inside their organization.

Leadership in nonprofit organizations uses positive work environments and team development as strategies to expand and grow their organization. Team effectiveness has two significant components, which are team development and team performance. Team effectiveness leads to efficient use of resources, improved productivity, increased innovation, improved problem-solving, improved decision-making, and better-quality products and services (Northouse, 2016). Leaders of nonprofit organizations pursuing growth and expansion, even sustainability, need to make team development a priority in their organization. Effective team development leads to effective communication, better collaboration, and efficient teamwork (Suprapto, 2017). Employees' performance in organizations improves with team effectiveness, joined with communication and cooperation (Suprapto, 2017).

Strategies for growth and expansion of a nonprofit organization can help sustain a company into the likely future and impact positive social change in organizations, communities, individuals, the environment, and society. The impli- 
cations for positive social change include providing growth and expansion strategies leaders of nonprofit organizations can use to increase their capacity for positively altering communities by increasing accessible opportunities and services to individuals and organizations.

The right working environment has a profound impact and influences employee morale. Böckerman and Ilmakunnas (2020) postulated positive working situations are the basis for employee job satisfaction and employee loyalty. Blanaru and Medeleanu (2017) asserted that employee loyalty leads to exceptional organizational performance. Researchers have recognized an association between employee loyalty and organizational performance.

\section{Conflicts of Interest}

The author declares no conflicts of interest regarding the publication of this paper.

\section{References}

Abdalla, M., Oliveira, L., Azevedo, C., \& Gonzalez, R. (2018). Quality in Qualitative Organizational Research: Types of Triangulation as a Methodological Alternative. Administration: Teaching and Research [Administração: Ensino e Pesquisa], 19, 66-98. https://doi.org/10.13058/raep.2018.v19n1.578

Akaeze, C. O. (2016). Exploring Strategies Required for Small Business Sustainability in Competitive Environments. Doctoral Dissertation, Minneapolis, MN: Walden University.

Alavi, M., Archibald, M., McMaster, R., Lopez, V., \& Cleary, M. (2018). Aligning Theory and Methodology in Mixed Methods Research: Before Design Theoretical Placement. International Journal of Social Research Methodology, 21, 527-540. https://doi.org/10.1080/13645579.2018.1435016

Appe, S. (2019). Nonprofit Organizations as Interpretive Communities: Responses to Policy Reforms and the Shaping of Civil Society in Ecuador. Policy Studies, 40, 609-627. https://doi.org/10.1080/01442872.2018.1533115

Baldrige Performance Excellence Framework (2018). 2017-2018 Baldrige Excellence Framework: A Systems Approach to Improving Your Organization's Performance. Gaithersburg, MD: U.S. Department of Commerce, National Institute of Standards and Technology. http://www.nist.gov/baldrige

Baumol, W. J. (2015). Joseph Schumpeter: The Long Run, and the Short. Journal of Evolutionary Economics, 25, 37-43. https://doi.org/10.1007/s00191-013-0327-3

Bello, B., \& Ivanov, S. (2014). Growth Strategies for Very Small Organizations: A Case Study of a Very Small Entrepreneurship. International Journal of Organizational Innovation, 6, 51-53.

https://www.scribd.com/document/307202520/International-Journal-of-Organisational -Innovation-Final-Issue-Vol-6-Num-4-April-2014

Bennett, R. (2016). Factors Contributing to the Early Failure of Small New Charity Start-Ups. Journal of Small Business and Enterprise Development, 23, 333-348. https://doi.org/10.1108/JSBED-11-2013-0173

Birt, L., Scott, S., Cavers, D., Campbell, C., \& Walter, F. (2016). Member Checking: A Tool to Enhance Trustworthiness or Merely a Nod to Validation. Qualitative Health 
Research, 26, 1802-1811. https://doi.org/10.1177/1049732316654870

Blackburn, R. A., Hart, M., \& Wainwright, T. (2013). Small Business Performance: Business, Strategy, and Owner-Manager Characteristics. Journal of Small Business and Enterprise Development, 20, 8-27. https://doi.org/10.1108/14626001311298394

Blanaru, R. A., \& Medeleanu, C. (2017). Determinant Factors of Organizational Performance in the North-East Reginald Development Agency. Analele Ştiințifice ale Universității »Alexandru Ioan Cuza» din Iaşi. Sociologie şi Asistență Socială, 20, 24-38. https://www.ceeol.com/search/article-detail?id=662829

Böckerman, P., \& Ilmakunnas, P. (2020). Do Good Working Conditions Make You Work Longer? Analyzing Retirement Decisions Using Linked Survey and Register Data. The Journal of Economics of Ageing, 17, Article ID: 100192. https://doi.org/10.1016/j.jeoa.2019.02.001

Boddy, C. R. (2016). Sample Size for Qualitative Research. Qualitative Market Research: An International Journal, 19, 426-432. https://doi.org/10.1108/QMR-06-2016-0053

Broks, A. A. (2016). Systems Theory of Systems Thinking: General and Particular within Modern Science and Technology Education. Journal of Baltic Science Education, 15, 408-410. http://www.scientiasocialis.lt/jbse/view/biblio/year/2016/volume/15/issue/4

Campbell, J. M., \& Park, J. (2017). Extending the Resource-Based View: Effects of Strategic Orientation toward Community on Small Business Performance. Journal of Retailing and Consumer Services, 34, 302-308.

https://doi.org/10.1016/j.jretconser.2016.01.013

Cavan, D. R. (2016). Analyzing Retail Store Closures. Appraisal Journal, 84, 353-360. https://www.appraisalinstitute.org/

Caws, P. (2015). GST: Its Past and Potential. Systems Research and Behavioral Science, 32, 514-521. https://doi.org/10.1002/sres.2353

Celec, R., \& Globocnik, D. (2017). Benchmarking Firm-Level Resources, Capabilities, and Postures Driving Export Performance of SMEs. Nase Gospodarstvo, 63, 47-58. https://doi.org/10.1515/ngoe-2017-0005

Ceric, A. (2015). Bringing Together Evaluation and Management of ICT Value: A Systems Theory Approach. Electronic Journal of Information Systems Evaluation, 18, 19-35. http://www.academic-conferences.org

Chen, L. (2016). Benefits and Dynamics of Learning Gained through Volunteering: A Qualitative Exploration Guided by Seniors' Self-Defined Successful Aging. Educational Gerontology, 42, 220-230. https://doi.org/10.1080/03601277.2015.1108150

Chiniara, M., \& Bentein, K. (2016). Linking Servant Leadership to Individual Performance: Differentiating the Mediating Role of Autonomy, Competence and Relatedness Need Satisfaction. The Leadership Quarterly, 27, 124-141.

https://doi.org/10.1016/j.leaqua.2015.08.004

Choi, S. (2016). An Inside-Out Marketing Strategy for Innovation among Human Service Nonprofits in South Korea. Nonprofit Management \& Leadership, 26, 331-347. https://doi.org/10.1002/nml.21196

Choi, T., Rupasingha, A. A., Robertson, J. C., \& Green Leigh, N. (2017). The Effects of High Growth on New Business Survival. Review of Regional Studies, 47, 1-23. https://www.srsa.org/rrs

Coad, A. (2014). Death Is Not a Success: Reflections on Business Exit. International Small Business Journal, 32, 721-732. https://doi.org/10.1177/0266242612475104

Debono, D., Greenfield, D., Testa, L., Mumford, V., Hogden, A., Pawsey, M., \& Braith- 
waite, J. (2017). Understanding Stakeholders' Perspectives and Experiences of General Practice Accreditation. Health Policy, 121, 816-822. https://doi.org/10.1016/j.healthpol.2017.05.006

Decker, P., Haltiwanger, J., Jarmin, R., \& Miranda, J. (2014). The Role of Entrepreneurship in Us Job Creation and Economic Dynamism. Journal of Economic Perspectives, 28, 3-24. https://doi.org/10.1257/jep.28.3.3

Drake, M., \& Schwarz, G. (2010). Recent Developments in General System Theory. Systems Research and Behavioral Science, 27, 601-610. https://doi.org/10.1002/sres.1013

Duan, N., Bhaumik, D., Palinkas, L., \& Hoagwood, K. (2014). Optimal Design and Purposeful Sampling: Complementary Methodologies for Implementation Research. Administration and Policy in Mental Health and Mental Health Services Research, 42, 524-532. https://doi.org/10.1007/s10488-014-0596-7

East, R. (2016). Bias in the Evaluation of Research Methods. Marketing Theory, 16, 219-231. https://doi.org/10.1177/1470593115609797

Fantazy, K. A., Tipu, S. A. A., \& Kumar, V. (2016). Conceptualizing the Relative Openness of Supply Chain and Its Impact on Organizational Performance. Benchmarking: An International Journal, 23, 1264-1285. https://doi.org/10.1108/BIJ-05-2015-0045

Franca, M. L., de Aragao Gomes, I. M., Machado, G. C., \& Russo, S. L. (2014). Factors Conditioning Failure of Micro and Small Businesses of the Information Technology and Communication (ICT): Study of Multiple Cases, Aracaju (SE), Brazil. Business Management Dynamics, 3, 40-50. http://bmdynamics.com/page.php?name=Archive/

Fusch, P., \& Ness, L. (2015). Are We There Yet? Data Saturation in Qualitative Research. Qualitative Report, 20, 1408-1416. https://nsuworks.nova.edu/tqr/vol20/iss9/3

Ganapathy, M. (2016). Qualitative Data Analysis: Making It Easy for Nurse Researcher. International Journal of Nursing Education, 8, 106-110.

Garza, F. A. (2013). A Framework for Strategic Sustainability in Organizations: A Three Pronged Approach. Journal of Comparative International Management, 16, 23-36. http://www.erudit.org/revue/jcim

Ghorbal-Blal, I. (2011). The Role of Middle Management in the Execution of Expansion Strategies: The Case of Developers' Selection of Hotel Projects. International Journal of Hospitality Management, 30, 272-282. https://doi.org/10.1016/j.ijhm.2010.09.007

Gilbert, M. (2017). Bracing for Their Next Audit; Now Is the Time for Nonprofits to Review Systems and Processes. Accounting Today, 31, 5-8. https://www.accountingtoday.com/

Gökalp, E., \& Demirörs, O. (2017). Model Based Process Assessment for Public Financial and Physical Resource Management Processes. Computer Standards \& Interfaces, 54, 186-193. https://doi.org/10.1016/j.csi.2016.11.011

Greenspan, A., \& Wooldridge, A. (2018). Capitalism in America: A History. New York, NY: Penguin Press.

Guetterman, T. C., \& Fetters, M. D. (2018). Two Methodological Approaches to the Integration of Mixed Methods and Case Study Designs: A Systematic Review. American Behavioral Scientist, 62, 900-918. https://doi.org/10.1177/0002764218772641

Gummer, E. S., \& Mandinach, E. B. (2015). Building a Conceptual Framework for Data Literacy. Teachers College Record, 117, 1-22.

https://www-tcrecord-org.ezp.waldenulibrary.org/library

Gumusluoglu, L., \& Acur, N. (2016). Fit among Business Strategy, Strategy Formality, and Dynamic Capability Development in New Product Development. European Manage- 
ment Review, 13, 107-123. https://doi.org/10.1111/emre.12070

Hibbler-Britt, L., \& Sussan, F. (2015). Small Business Success and Social Capital: A Multicultural Approach. International Journal of Business \& Finance Research, 10, 156-163. https://d1wqtxts1xzle7.cloudfront.net/43630787/Financial Aspects of Determining Opti mal20160311-20624-11rq240.pdf?1457717508=\&response-content-disposition=inline\%3B+ filename\%3DFinancial Aspects of Determining Optimal.pdf\&

Hitt, M. A., Xu, K., \& Carnes, C. M. (2016). Resource Based Theory in Operations Management Research. Journal of Operations Management, 41, 77-94.

https://doi.org/10.1016/j.jom.2015.11.002

Ifekwem, N., \& Adedamola, O. (2016). Survival Strategies and Sustainability of Small and Medium Enterprises in the Oshodi-Isolo Local Government Area of Lagos State. Acta Universitatis Sapientiae: Economics and Business, 4, 103-118.

https://doi.org/10.1515/auseb-2016-0006

Irvine, D., \& Irvine, S. (2016). The Practice of Quality: Changing General Practice. London, England: CRC Press. https://doi.org/10.1201/9781315377308

Joyce, W. F., \& Slocum, J. W. (2012). Top Management Talent, Strategic Capabilities, and Firm Performance. Organizational Dynamic, 41, 193-193.

https://doi.org/10.1016/j.orgdyn.2012.03.001

Kang, M. (2016). Moderating Effects of Identification on Volunteer Engagement: An Exploratory Study of a Faith-Based Charity Organization. Journal of Communication Management, 20, 102-117. https://doi.org/10.1108/JCOM-08-2014-0051

Kast, F. E., \& Rosenzweit, J. E. (1972). General System Theory: Application for Organization and Management. Academy of Management Journal, 15, 447-465.

Kroll, J. (2017). Requisite Participant Characteristics for Effective Peer Group Mentoring. Mentoring \& Tutoring: Partnership in Learning, 25, 78-96. https://doi.org/10.1080/13611267.2017.1308096

Lan, Y., Bo, Y., \& Baozhen, Y. (2014). Core Business Selection Based on Ant Colony Clustering Algorithm. Mathematical Problems in Engineering, 2014, Article ID: 136753. https://doi.org/10.1155/2014/136753

Landles-Cobb, L., Kramer, K., \& Milway, K. S. (2016). Nonprofit Leader's Exodus. Leadership Excellence Essentials, 33, 11-12.

https://www.hr.com/en/topleaders/top leaders in leadership/leadership excellence es sentials/

Leonidou, L., Christodoulides, P., Kyrgidou, L., \& Palihawadana, D. (2017). Internal Drivers and Performance Consequences of Small Firm Green Business Strategy: The Moderating Role of External Forces. Journal of Business Ethics, 140, 585-606. https://doi.org/10.1007/s10551-015-2670-9

Levy, M. (2015). The Role of Qualitative Approaches to Research in Call Contexts: Closing in on the Learner's Experience. Computer Assisted Language Instruction Consortium Journal, 32, 554-568. https://doi.org/10.1558/cj.v32i3.26620

Lewis, S. (2015). Qualitative Inquiry and Research Design: Choosing among Five Approaches. Health Promotion Practice, 16, 473-475.

https://doi.org/10.1177/1524839915580941

Lincoln, Y. S., \& Guba, E. G. (1985). Naturalistic Inquiry. Newbury Park, CA: Sage Publications, Inc.

Luo, T., \& Stark, P. B. (2015). Nine Out of 10 Restaurants Fail? Check, Please. Significance, 12, 25-29. https://doi.org/10.1111/j.1740-9713.2015.00813.x 
Malecic, A. (2017). Footprints of General Systems Theory. Systems Research and Behavioral Science, 34, 631-636. https://doi.org/10.1002/sres.2484

Manso, G. (2017). Creating Incentives for Innovation. California Management Review, 60, 18-32. https://doi.org/10.1177/0008125617725287

Marshall, C., \& Rossman, G. (2016). Designing Qualitative Research (5th ed.). Thousand Oaks, CA: Sage.

Mellat-Parast, M., Golmohammadi, D., McFadden, K. L., \& Miller, J. W. (2015). Linking Business Strategy to Service Failures and Financial Performance: Empirical Evidence from the U.S. Domestic airline Industry. Journal of Operations Management, 38, 14-24. https://doi.org/10.1016/j.jom.2015.06.003

Mihaela, H. (2017). Drivers of Firm Performance: Exploring Quantitative and Qualitative Approaches. Studies in Business \& Economics, 12, 79-84. https://doi.org/10.1515/sbe-2017-0006

Miracle, V. A. (2016). The Belmont Report: The Triple Crown of Research Ethics. Dimensions of Critical Care Nursing, 35, 223-228.

https://doi.org/10.1097/DCC.0000000000000186

Momani, A. M., Al-Hawari, T. H., \& Mousa, R. W. (2016). Using Expanded Real Options Analysis to Evaluate Capacity Expansion Decisions under Uncertainty in the Construction Material Industry. South African Journal of Industrial Engineering, 24, 1-14. https://doi.org/10.7166/27-2-1381

Monelos, P. L., Sanchez, C. P., \& Lopez, M. R. (2014). DEA as a Business Failure Prediction Tool Application to the Case of Galician SMEs. Contaduria y Administracion, 59, 65-96. https://doi.org/10.1016/S0186-1042(14)71255-0

Morgan, J., \& Sisak, D. (2016). Aspiring to Succeed: A Model of Entrepreneurship and Fear of Failure. Journal of Business Venturing, 31, 1-21.

https://doi.org/10.1016/j.jbusvent.2015.09.002

Mourão, P., Pereira, T., \& Moreira, M. C. (2017). The Importance of New Forms of Capital in Nonprofit Organizations: A Case Study of the Fafe Delegation of the Portuguese Red Cross. International Journal of Social Economics, 44, 846-868. https://doi.org/10.1108/IJSE-09-2015-0240

Noble, H., \& Smith, J. (2015). Issues of Validity and Reliability in Qualitative Research. Evidence-Based Nursing, 18, 34-35.

Northouse, P. G. (2016). Team Leadership. In Leadership: Theory and Practice (7th ed., pp. 362-396). Thousand Oaks, CA: Sage.

Palmer, J. C., Wright, R. E., \& Powers, J. B. (2001). Innovation and Competitive 144 Advantage in Small Businesses: Effects of Environments and Business Strategy. Journal of Small Business Strategy, 12, 30-41.

https://libjournals.mtsu.edu/index.php/jsbs/article/view/464

Park, J., \& Park, M. (2016). Qualitative versus Quantitative Research Methods: Discovery or Justification? Journal of Marketing Thought, 3, 2-7.

Perry Jr., N. S. (1972). General System Theory: An Inquiry into Its Social Philosophy. Academy of Management Journal, 15, 495-510. https://doi.org/10.5465/255144

Phillips, A., Borry, P., \& Shabani, M. (2017). Research Ethics Review for the Use of Anonymized Samples and Data: A Systematic Review of Normative Documents. Accountability in Research: Policies \& Quality Assurance, 24, 483-496.

https://doi.org/10.1080/08989621.2017.1396896

Pugna, A., Miclea, S., Negrea, R., \& Potra, S. (2016). Small Business Owners Undertaking 
Organized Marketing Activities: Out of Need or Available Resources? Procedia Computer Science, 91, 306-313. https://doi.org/10.1016/j.procs.2016.07.083

Ridder, H.-G. (2017). The Theory Contribution of Case Study Research Designs. Business Research, 10, 281-305. https://doi.org/10.1007/s40685-017-0045-Z

Robinson, O. C. (2014). Sampling in Interview-Based Qualitative Research: A Theoretical and Practical Guide. Qualitative Research in Psychology, 11, 25-41. https://doi.org/10.1080/14780887.2013.801543

Ross, M. W., Iguchi, M. Y., \& Panicker, S. (2018). Ethical Aspects of Data Sharing and Research Participant Protections. American Psychologist, 73, 138-145. https://doi.org/10.1037/amp0000240

Roth, W. F. (2015). Strategic Planning as an Organization Design Exercise. Performance Improvement, 54, 6-12. https://doi.org/10.1002/pfi.21487

Rousseau, D. (2017). Strategies for Discovering Scientific. Systems Research \& Behavioral Science, 34, 527-536. https://doi.org/10.1002/sres.2488

Saini, D., \& Sengupta, S. S. (2016). Responsibility, Ethics, and Leadership: An Indian Study. Asian Journal of Business Ethics, 5, 97-109. https://doi.org/10.1007/s13520-016-0058-2

Saldana, J. (2015). The Coding Manual for Qualitative Researchers. Thousand Oaks, CA: Sage Publications.

Sanzo-Perez, M. J., Rey-García, M., \& Álvarez-González, L. I. (2017). The Impact of Professionalization and Partnerships on Nonprofit Productivity. The Service Industries Journal, 37, 783-799. https://doi.org/10.1080/02642069.2017.1353976

Sargeant, A., \& Shang, J. (2017). Fundraising Principles and Practice (2nd ed.). Hoboken, NJ: Wiley. https://doi.org/10.1002/9781119228974

Sassen, S. (2016). Economic Cleansing: Failure Dressed in Fine Clothes. Social Research, 83, 673-687. https://www.socres.org/issues/category/Back\%20Issues/

Saunders, M. N. K., Lewis, P., \& Thornhill, A. (2015). Research Methods for Business Students (7th ed.). Essex, England: Pearson Education Limited.

Scherger, V., Vigier, H. P., \& Barbera-Marine, M. (2014). Finding Business Failure Reasons through a Fuzzy Model of Diagnosis. Fuzzy Economic Review, 19, 45-62.

http://www.sigef.net/2014-09-26-07-16-23/summaries-and-abstracts/itemlist/category/ 168-number-1-may-2014/ https://doi.org/10.25102/fer.2014.01.04

Siddiqui, S. (2018). Let Not-for-Profits Be Innovative, Willing to Fail. Indianapolis Business Journal, 39, 10B-11B. https://www.ibj.com/

Starr, M. A. (2014). Qualitative and Mixed-Methods Research in Economics: Surprising Growth, Promising Future. Journal of Economic Surveys, 28, 238-264. https://doi.org/10.1111/joes.12004

Stecker, M. J. (2014). Revolutionizing the Nonprofit Sector through Social Entrepreneurship. Journal of Economic Issues, 48, 349-357. https://doi.org/10.2753/JEI0021-3624480208

Stephan, U., Patterson, M., Kelly, C., \& Mair, J. (2016). Organizations Driving Positive Social Change: A Review and an Integrative Framework of Change Processes. Journal of Management, 42, 1250-1281. https://doi.org/10.1177/0149206316633268

Suprapto, W. (2017). The Influence of Individual Knowledge and Work Team Development to the Manufacturing Company Performance of East Java. Jurnal Manajemen dan Kewirausahaan, 19, 22-27. https://doi.org/10.9744/jmk.19.1.22-27 
Thomas, D. (2017). Feedback from Research Participants: Are Member Checks Useful in Qualitative Research? Qualitative Research in Psychology, 14, 23-41. https://doi.org/10.1080/14780887.2016.1219435

U.S. Small Business Administration, Office of Advocacy (2016). Small Business Profiles for the States and Territories. https://www.sba.gov/advocacy

U.S. Small Business Administration, Office of Advocacy (2017). What's New with Small Business? https://advocacy.sba.gov/

Valentinov, V., \& Chatalova, L. (2014). Transaction Costs, Social Costs and Open Systems: Some Common Threads. Systems Research \& Behavioral Science, 31, 316-326. https://doi.org/10.1002/sres.2204

Van den Berg, A., \& Struwig, M. (2017). Guidelines for Researchers Using an Adapted Consensual Qualitative Research Approach in Management Research. Electronic Journal of Business Research Methods, 15, 109-119.

http://www.academic-conferences.org/ejournals.htm

Varpio, L., \& Meyer, H. (2017). A Lesson from the Qualitative Rip out Series: Let Go of Expectations from Universally Applicable “Gold Standards” for Qualitative Research. Journal of Graduate Medical Education, 9, 154-156. https://doi.org/10.4300/JGME-D-17-00014.1

Vaughn, P., \& Turner, C. (2016). Decoding via Coding: Analyzing Qualitative Text Data through Thematic Coding and Survey Methodologies. Journal of Library Administration, 56, 41-51. https://doi.org/10.1080/01930826.2015.1105035

Von Bertalanffy, L. (1950). The Theory of Open Systems in Physics and Biology. Science, 111, 23-29. https://doi.org/10.1126/science.111.2872.23

Von Bertalanffy, L. (1953). An Outline of GST. British Journal for the Philosophy of Science, 1, 134-165. https://doi.org/10.1093/bjps/I.2.134

Von Bertalanffy, L. (1968). GST: Foundations, Development, Applications. New York, NY: George Braziller.

Von Bertalanffy, L. (1972). The History and Status of GST. Academy of Management Journal, 15, 407-426. https://doi.org/10.5465/255139

Walden University (2017). Center for Research Quality: Research Ethics \& Compliance. http://academicguides.waldenu.edu/researchcenter

Wang, L., Gopal, R., Shankar, R., \& Pancras, J. (2015). On the Brink: Predicting Business Failure with Mobile Location-Based Checkins. Decision Support Systems, 76, 3-13. https://doi.org/10.1016/j.dss.2015.04.010

Windsong, E. A. (2018). Incorporating Intersectionality into Research Design: An Example Using Qualitative Interviews. International Journal of Social Research Methodology, 21, 135-147. https://doi.org/10.1080/13645579.2016.12683612

Yazan, B. (2015). Three Approaches to Case Study Methods in Education: Yin, Merriam, and Stake. The Qualitative Report, 20, 134-152. https://nsuworks.nova.edu/tqr/vol20/iss2/12/

Yin, R. K. (2018). Case Study Research and Applications: Design and Methods (6th ed.). San Francisco, CA: Sage.

Yusuf, A., \& Schindehutte, M. (2000). Exploring Entrepreneurship in a Declining Economy. Journal of Developmental Entrepreneurship, 5, 41-56.

http://www.worldscinet.com/jde 